\title{
How Does Cooperative Willingness Affect Innovation Achievements Transformation of University-industry Collaboration
}

\author{
Meng-Xue Qiao ${ }^{1, a}$, Yun-Mei Li ${ }^{2, b,{ }^{*}}$ \\ ${ }^{1}$ Center for Industrial Policy and Management Research, Wuhan University of Science and \\ Technology, No.947, Heping Avenue, Qingshan District, Wuhan, China \\ ${ }^{2}$ Center for Industrial Policy and Management Research, Wuhan University of Science and \\ Technology,123-116-2,Gangdu Garden, Qingshan District, Wuhan, China \\ a15527911732@163.com, 'blymwust@163.com \\ ${ }^{*}$ Corresponding author
}

Keywords: University-industry collaboration, Cooperative willingness, Achievements transformation, SEM.

\begin{abstract}
In order to encourage independent innovation and promote transformation of development relying on the progress of science and technology, the model of the university-industry collaboration has gradually become the mutual recognition. As a result, the willingness of collaboration has reached unprecedented heights and the collaborative innovation investment has been increasing. However, the achievement transformation of collaborative innovation was still unsatisfactory. High willingness to cooperate did not lead to high achievements transformation. So how does the cooperative willingness affecting on achievement transformation? Therefore, the authors explore the mechanism of cooperative willingness to innovation achievements transformation based on questionnaires and SEM. The research results show that cooperative willingness does not have significant positive effects on achievements transformation. Moreover, the cooperative willingness, as the premise of collaborative innovation, is a necessary but not sufficient condition of achievements transformation. Relevant policy suggestions are given based on the study.
\end{abstract}

\section{Introduction}

Innovation has been paid more attention by all types of enterprises due to globalization and commercialization. Furthermore, China is at an important stage of deepening reform, "collaborative innovation" and "cooperative" have received unprecedented attention. During the "Eleventh Five-Year" period, there is an increasing number of research cooperation project as well as funds, and the desire for cooperation has also grown stronger. However, the conversion rate of high-tech achievements remains to be unsatisfactory, and there exist large gaps with the developed countries. So, whether the cooperative willingness has any impact on achievements transformation or not? If it is, what is the impact? A lot literature was analyzed on this issue.

University-industry collaboration has stimulated a rich stream of literature. The extensive literature on university-industry collaboration is mainly theoretical study and empirical analysis. Taking an overview of related research, we have found that the empirical study on the relationship between willingness and achievements transformation of collaboration is much limited. So, the authors will explore the mechanism of how cooperative willingness affecting achievements transformation of the university-industry collaboration by means of structural equation modeling, aiming to recognize the core elements and provide some theoretical guidance for university-industry collaboration.

\section{Theory and Hypothesis}

Enterprise resources were first studied by Penrose in 1959. He stated that every organization is an accumulation of bunches of resources, and its internal aspects should be paid much attention when 
analyzing its competitive advantages and growth propensity.

Internal resources such as funds, human capital, technology, equipment are the primary factors of collaborative innovation that drive firms to seek partners as well as to realize achievements transformation. Usually, large-scale firms have a higher probability of collaboration with universities, because the large-scale enterprise has abundant internal resources to continuously support collaborative innovation behavior[1]. Hence, it is expected that internal resources are the material basis of collaborative innovation for enhancing the willingness to cooperate and for promoting achievements transformation of collaboration. This leads to the following hypothesis:

$\mathrm{H} 1$ : internal resources positively influence cooperative willingness.

$\mathrm{H} 2$ : internal resources positively influence achievements transformation.

Although enterprises and universities play different roles in the process of collaboration, seeking and realizing their interests are the internal driving force to participate in innovation activities. Moreover, collaborative innovation often involves high transaction costs and risks such as high innovation costs, long feedback times and uncertainty outcomes [2]. So, Profit adds the significance to the linkage of the firms to universities not only to acquire resources but also to strength lateral communication. Cost-sharing and risk-sharing are the key factors affecting firms' decision to cooperate with others [3-4]. Firms that feel such barriers would have a higher motivation to seek collaboration with universities. Hence, this leads to the following assumptions:

H3: Profit produces a positive effect on the cooperative willingness.

Environment refers to series of external motivators which play a catalytic role in affecting their willingness to cooperate [5]. Rapid technological change, market demand, intense global competition and short product life cycle have radically transformed the current competitive environment [6]. Such complex environment has exerted enormous burdens on them to seek relationships with partners to enable them to remain at the leading edge in all areas for most firms and universities. Moreover, governments have been propelled into the struggle and have to take actions to support university-industry collaboration as governments believe that innovation could aid in economic regeneration. Hence, it is expected that external environment forces them to seek partners continuously, and increase their willingness to cooperate. This leads to the following assumptions:

H4: Environment produces a positive effect on the cooperative willingness.

Values can be regarded as same strategic goals that guide their value standpoint and behavioral approach in the process collaboration. Plewa[7]claimed that the value orientation covers their common goals as well as the same concepts of operations.

Obviously, there are real differences between industries and universities in values because the different interests and complex cooperative relationship. Therefore, identification with their goals and values plays a positive role in maintaining their relationship and promoting achievements transformation. Values work by guiding their individual behavior to group behavior, and driving their collaborative innovation to achieve consistency desired goals. Deep cooperation can hardly carry out without strategic collaboration, which includes the collaboration between industry and academia on the values and culture. Hence, it is expected that value orientation can guide the collaborators sharing the same strategic target and pushing the achievements transformation. This leads to the following assumptions:

H5: value orientation produces a positive effect on the achievements transformation.

Cooperative willingness explains the initiative and openness that collaborators participate in external activities seek external resources and search for new partners. Cooperative willingness is an obvious signal of enterprises and universities to participate in collaboration activities. Cooperative willingness refers here to the broad set of activities that firms acquire knowledge, voluntarily disclose knowledge to and exchange knowledge with the external world [8]. Willingness to cooperate can inspire their initiative to look for partners and their enthusiasm to cooperate with others, and it is the precondition of realizing achievements transformation. Hence, it is expected that cooperative willingness has an influence on technical knowledge transfer and achievements transformation. This leads to the following assumptions: 
H6: cooperative willingness positively affects the collaborative achievements transformation.

In addition, achievements transformation is usually measured in three aspects: new products and devices, improvement of industrial products, improvement of industrial process [9].

\section{Study Design}

\section{The Study Sample}

Data were collected from enterprises and universities by questionnaires in China. Specific managers and employees who were engaged in collaborative innovation were selected for the survey. In this study, 216 questionnaires were collected by the scene and web. After excluding the incomplete ones, 193 valid questionnaires data were used to conduct this research, and the valid response rate was $89.4 \%$.

\section{Variable Measuring}

We measured internal resources with four items by modifying the Adebowale(2012) and Eom's(2010) related scales. Two items referring to cost-sharing and risk-sharing were used to measure the profit and four items were used to measure the environmental by adapting Veugelers's (2005) and Adebowale's(2012) scales. We measured values with two items by modifying and adapting Plewa and Quester's(2007) scales. Cooperative willingness were divided into three dimensions and was measured by Fontana \& Geuna's(2006) scales. We measured transformation of achievements with three items by adapting Eom \& Lee's (2010) scales.

\section{Data Analysis}

\section{Data Reliability and Validity Analysis}

Before testing our hypothesis, the reliability and validity of the scale were tested. For this research, Cronbach alphas were measured and given in table 1 and Bartlett sphere test were measured and given in table 2.

Tab.1 Reliability Analysis

\begin{tabular}{|c|c|c|}
\hline latent variable & Manifest variables & Cronbach's $\alpha$ \\
\hline \multirow{2}{*}{ profit-driven } & Cost-sharing (X1) & \multirow{2}{*}{.802} \\
\hline & Risk-sharing (X2) & \\
\hline \multirow{2}{*}{ values } & common goals (X3) & \multirow{2}{*}{.814} \\
\hline & consistent operating concept $(\mathrm{X} 4)$ & \\
\hline \multirow{4}{*}{ internal resources } & capital (X5) & \multirow{4}{*}{.898} \\
\hline & technology (X6) & \\
\hline & facility (X7) & \\
\hline & human capital (X8) & \\
\hline \multirow{4}{*}{$\begin{array}{c}\text { Environmental- } \\
\text { driven }\end{array}$} & technology advancements (X9) & \multirow{4}{*}{.858} \\
\hline & market requirement $(\mathrm{X} 10)$ & \\
\hline & competition pressure (X11) & \\
\hline & government support (X12) & \\
\hline \multirow{3}{*}{$\begin{array}{l}\text { cooperation } \\
\text { willingness }\end{array}$} & acquire knowledge and technology(Y1) & \multirow{3}{*}{.842} \\
\hline & Involve in public activities (Y2) & \\
\hline & disclose knowledge with the external (Y3) & \\
\hline \multirow{3}{*}{$\begin{array}{l}\text { achievements } \\
\text { transformation }\end{array}$} & new products and devices(Y4) & \multirow{3}{*}{.791} \\
\hline & improvement of industrial products (Y5) & \\
\hline & improvement of industrial process (Y6) & \\
\hline
\end{tabular}

Table 1 and table 2 indicate that this questionnaire is acceptable and reliable as Cronbach alpha values for all data are greater than 0.75, KM0 value is 0.954 , and significant probability of Bartlett's Test is 0.000 . 
Tab.2 KMO and Bartlett Sphere Test

\begin{tabular}{c|c|c}
\hline \multicolumn{3}{c}{ KMO and Bartlett sphere Test } \\
\hline Sampling enough degrees of Kaiser - Meyer - Olkin measurements & .954 \\
\hline \multirow{3}{*}{ Bartlett sphericity test } & The approximate chi-square & 2222.506 \\
\cline { 2 - 3 } & df & 153 \\
\cline { 2 - 3 } & Sig. & .000 \\
\hline
\end{tabular}

\section{Path Analysis}

Data were analyzed with AMOS17.0 based on the structural equation modelling. The model of adaptation degree is shown in table 3 below.

Tab.3 Model Adaptation Degree Index

\begin{tabular}{c|c|c|c|c|c}
\hline $\begin{array}{c}\text { chi-square } \\
\text { value }\end{array}$ & P-value & AGFI & GFI & RMSEA & CN \\
\hline 197.740 & 0.000 & 0.857 & 0.897 & 0.056 & 157 \\
\hline
\end{tabular}

As is showed in table 3 in the initial hypothesis model, AGFI $<0.9$, GFI $<0.9$, RMSEA $<0.5$, CN $<200$, p value $=0.000<0.05$, and they all reach the significance level. So null hypothesis should be refused and the hypothesis model and the observation data cannot be fitted very well. Therefore, the model needs to be further revised. A good fit of model to the date was established based on Modified Index, leading to a non-significant $\chi^{2}(\mathrm{p}<0.05)$, a RMSEA value $(=0.031)$ close to 0.05 , as well as other fit indexes indicating a high degree of goodness-to-fit (AGFI=0.896, GFI=0.929).

Tab.4 The Modified Model Adaptation Degree Index

\begin{tabular}{c|c|c|c|c|c}
\hline chi-square value & P-value & AGFI & GFI & RMSEA & CN \\
\hline 138.682 & 0.084 & 0.896 & 0.929 & 0.031 & 215 \\
\hline
\end{tabular}

Fig.1 shows the results of standardized path coefficients estimates and significance test using structural equation modelling.

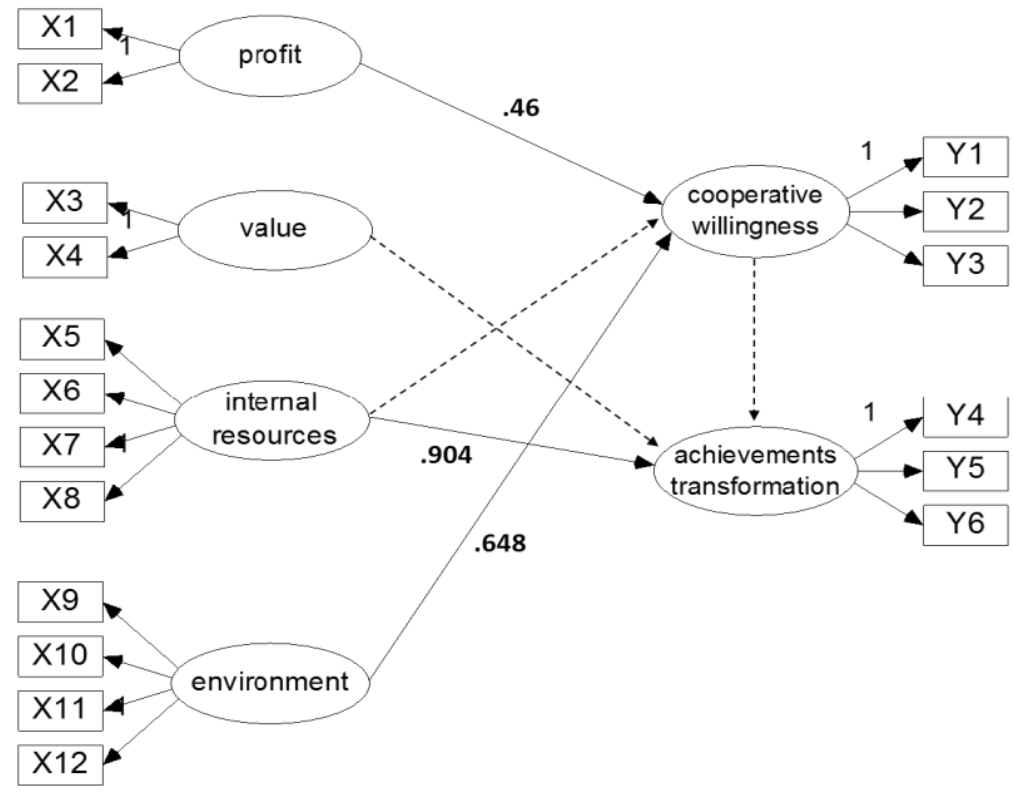

Fig.1 the re-specified model

The result in table 5 indicate a strong and significant influence of profit, environment on cooperative willingness $(H 3, p<0.001 ; H 4, p<0.01)$. The influence of internal recourse on achievements transformation is also confirmed by our results $(H 2, p<0.01)$. No significant 
association between internal recourse and cooperative willingness, however, is found and $H 1$ is rejected. Similarly, value orientation and cooperative willingness is not found to significantly affect transformation, $\mathrm{H} 5$ and $H 6$ are rejected.

Tab.5 Path Coefficient and Testing of the Modified Mode

\begin{tabular}{|c|c|c|c|c|c|}
\hline hypothesis & $\begin{array}{c}\text { standardized } \\
\text { path } \\
\text { coefficient }\end{array}$ & S.E & C.R. & P & result \\
\hline H1: cooperation willingness <- Internal resources & 0.069 & 0.243 & 0.302 & 0.763 & False \\
\hline H2: achievement transformation <-Internal resources & 0.904 & 0.337 & 3.076 & $* *$ & True \\
\hline H3: cooperation willingness <-profit-driven & 0.46 & 0.164 & 3.297 & $* * *$ & True \\
\hline H4: cooperation willingness <-environmental-driven & 0.648 & 0.267 & 2.729 & $* *$ & True \\
\hline H5: achievement transformation <-value & 0.695 & 0.494 & 1.422 & 0.155 & False \\
\hline $\begin{array}{c}\text { H6: achievement transformation <cooperation } \\
\text { willingness }\end{array}$ & 0.631 & 0.690 & 0.982 & 0.326 & False \\
\hline
\end{tabular}

\section{Conclusion and Suggestion}

\section{Conclusion}

(1) Profit and environment have a significant positive impact on cooperative willingness. Analyses of the research show that the standardized path coefficient of profit on willingness is 0.46 , and the relationship is significant. Similarly, the standardized path coefficient of environment on the willingness is 0.648 , and it is significant. Our results demonstrate that enterprises and universities are more likely to cooperate with others when they have a strong desire to seek profits and are surrounded with heated environment. Meanwhile, it also implies that enterprises and universities identify their collaborative innovation opportunities based on their internal interests and external environment at the early stages of the cooperation. And then they will choose the appropriate partners and establish a new relationship of win-win cooperation according to their actual situation and innovation resources.

(2) Internal resources have positively direct influence on transformation of achievements. The standardized path coefficient of internal resources on the achievements transformation is 0.46 . This suggests that in the process of collaborative innovation, internal resources provide a very important material basis for further collaborative innovation and have significant positive effects on achievements transformation.

(3) Value orientation and cooperative willingness have not directly positively significant relation to the achievements transformation. Table shows the results of standardized path coefficient of willingness on the achievements transformation are 0.631 , and the relationship is not significant. That means there is no direct link between cooperative willingness and achievements transformation. The cooperative willingness, as the premise of collaborative innovation, is a necessary but not sufficient condition of achievements transformation. This result also explains the huge gap between number of collaborative projects and the conversion rate of achievements.

\section{Suggestions}

(1) Different characteristics should be paid attention in different stages of collaboration activities and different incentive policies should be taken. Since the willingness to cooperate is a necessary but not sufficient condition of achievements transformation, the phase differentiation should be recognized between the formation of cooperation and achievements transformation. The formation of the cooperative willingness -- the cooperative relationship is merely a stage of cultivation. During this stage, assessment interventions are supposed to be cut down; collaborative innovation culture which encourages innovation and tolerates failure ought to be developed, thus establishing a 
relaxed policy environment for the formation of a cooperative relationship of collaborative innovation.

(2) A collaborative innovation financing platform should be set up and community resources should be assembled to improve the internal resource construction level of university-Industry collaboration. Internal resources have a significant positive impact on the achievement transformation. Collaborative innovation is a long process with a high risk and high input, and is difficult for general funds to enter into the process. Talented personnel and the ample fund are not only the key to the smooth progress of collaborative innovation, but also the two core elements to achieve the transformation. The financing platform should be set up in order to integrate those superior resources to help enterprises and universities having good communication. Meanwhile, the problem of insufficient funds and the lack of talented personnel may be settled, which is a strong support for the innovation achievement transformation.

\section{Acknowledgement}

This research was financially supported by the Research Project of Humanities and Social Sciences in the Education Department of Hubei Province and Graduate Student Teaching Research Project of Wuhan University of Science and Technology.

\section{References}

[1] B. A. Adebowale, B. Oyelaran-Oyeyinka, University-Industry Collaboration as a Determinant of Innovation in Nigeria, J. International Journal of Institutions and Economies. 1 (2012) 21-46.

[2] A. J. Richard, G. Jerry, C. Marie, Disclosure and licensing of university inventions:"The best we can do with the s\&t we get to work with”, J. International Journal of Industrial Organization. 21 (2003) 1271-1300.

[3] B. Bigllard, P. Colacino, Innovative characteristics of small and medium enterprises, J. Journal of Technology Management \& Innovation. 6 (2011) 83-93.

[4] J.F. Wang, J.F. Shao, X.H. Ma, S. Wu, Y. Liu, Research on key power optimization of collaborative innovation based on data, J. Management Science in China. (2013) 731-737.

[5] P.C. Chen, M.Z. Tu, Research on innovation mechanism of technology alliance cooperation, J. technological progress and Countermeasures. 6 (2007) 37-39.

[6] R. Veugelers, B. Cassiman, R\&D Cooperation between Firms and Universities: Some empirical evidence from Belgian manufacturing, J. International Journal of Industrial Organization. 56 (2005):355-379.

[7] C. Plewa, P. Quester, Key drivers of university-industry relationships:the role of organisational compatibility and personal experience, J. Journal of Services Marketing. 21 (2007) 370-382.

[8] R. Fontana, A. Geuna, M, Matt, Factors affecting university-industry R\&D projects:The importance of searching, screening and signaling, J. Research Policy. 35 (2006) 309-323.

[9] B. Eom, K. Lee, Determinants of industry-academy linkages and their impact on firm performance:The case of Korea as a latecomer in knowledge industrialization, J. Research Policy. 5 (2010) 625-639. 